\title{
ÉTICA E XAMANISMO
}

\author{
ETHIQUE ET CHAMANISME
}

Roberto Starling*

Rafael Leopoldo**

\section{RESUMO}

O presente paper primeiro propõe uma ecologia do medo diante do antropoceno. Trata-se de sentir o medo in concreto como parece propor o xamã Davi Kopenawa ou o filósofo Günther Anders. Desta forma, podemos estar diante do real perigo do antropoceno. Após, a exposição dessa ecologia do medo nós analisamos a Guerra dos Mundos elaborada, inicialmente, por Bruno Latour e reelaborada por Eduardo Viveiros de Castro e Déborah Danowski. Nós pensamos na distinção entre os Humanos (os modernos) e os Terranos (o povo que falta). Por último, propomos voltar a análise das tecnologias de si proposta por Michel Foucault. Foucault no seu livro $A$ hermenêutica do sujeito produz uma genealogia do cuidado de si. Porém, o ponto não abordado dessa genealogia é que ela tem o seu início no xamanismo, assim, entramos na pré-história do cuidado de si para pensarmos um cuidado de si ameríndio na atualidade como possível resposta ao antropoceno.

PALAVRAS-CHAVE: Antropoceno; Gaia; Cuidado de si ameríndio; Xamanismo.

\section{RÉSUMÉ}

Cet paper propose d'abord une écologie de la peur face à l'anthropocène. Il s'agit de ressentir la peur in concreto comme semble le proposer le chaman Davi Kopenawa ou le philosophe Günther Anders. De cette façon, nous pouvons faire face au réel danger de l'anthropocène. Après, l'exposition de cette écologie de la peur, nous avons analysé la Guerre des Mondes, élaborée par Bruno Latour et réélaborée par Eduardo Viveiros de Castro et Déborah Danowski. Nous pensons sur la distinction entre les humains (les modernes) et les Terrans (le peuple qui manque). Enfin, nous proposons de revenir à l'analyse des technologies de soi proposées par Michel Foucault. Foucault dans son livre L'herméneutique du sujet produit une généalogie du soi. Cependant, le point non abordé dans cette généalogie est qu'elle a ses débuts dans le chamanisme, ainsi, nous sommes entrés dans la préhistoire du souci de soi pour penser aujourd'hui aux soucis de soi amérindiens comme une réponse possible à l'anthropocène.

MOTS CLÉS: Anthropocène; Gaia; Souci de soi amérindiens; Chamanisme.

\footnotetext{
* Doutor em Filosofia. Professor de filosofia da PUC Minas. E-mail: r.starling@ig.com.br.

** Mestre em psicologia pela Universidade Federal de Juiz de Fora (UFJF). Pós-graduado pela Faculdade Latino Americana de Ciências Sociais (FLACSO) e graduado em filosofia pela Pontifícia Universidade Católica de Minas Gerais (PUC-MG). E-mail: ralasfer@gmail.com.
} 


\section{INTRODUÇÃO}

La peur prouve que l'homme réfléchit

(Provérbio francês)

Neste artigo apresentamos uma noção de cuidado vinculada a um medo necessário; a uma heurística do medo que envolve tanto o saber ameríndio quanto a filosofia de Günther Anders. Primeiramente, o cuidado e o medo são apresentados como uma imposição para determinado zelo - uma relação ética - com o meio ambiente, ou ainda, com a Terra ${ }^{1}$, com Gaia. Estamos diante de uma Gaia-política com suas cartografias de guerra e paz. O medo sentido in concreto seria o afeto que nos alertaria para a catástrofe atual que tem como um dos seus nomes a palavra antropoceno, ou seja, o ser humano como agente geológico do nosso desastre ambiental. Catástrofe essa - do anthropo - soturnamente compartilhada com cada humano, com cada não humano, ou ainda, pós-humano.

Dessa primeira noção de cuidado apresentamos alguns aspectos da Guerra dos Mundos como apontada, primeiramente, por Bruno Latour e retomada mais agudamente por Eduardo Viveiros de Castro e Débora Danowski. Neste momento, no meio desta Guerra, regressamos novamente para a temática do catastrófico, na nossa relação com a natureza. É salientada a figura dos Humanos e dos Terranos, que compreendemos como os Modernos e a Cultura Ameríndia. É inevitável pensar ainda num un peuple qui manque ("um povo que falta"), concepção, sobretudo, de Félix Guattari. O tema da ética surge com relação à Terra, à Gaia, com relação a uma cosmopolítica, mas, também, com um determinado zelo, com um cuidado de si ameríndio, com uma forma de transformação do sujeito que envolve o acesso à verdade. Estamos diante de determinada espiritualidade desflorestada pela constituição moderna.

No sentido de aclararmos o conceito de cuidado de si regressamos à obra de Michel Foucault, A hermenêutica do sujeito. Compreendemos esse conceito, principalmente, vinculado ao pensamento grego e à figura de Sócrates. Todavia, compreendemos que o cuidado de si, as práticas de si, são anteriores ao pensamento filosófico socrático como, além

\footnotetext{
1 A todo o momento pensamos e esperamos evocar a duplicidade da palavra Terra/terra. A Terra enquanto planeta e a terra enquanto solo. Pensamos que é possível nos aterrarmos de forma desejante na Terra/terra.
} 
disso, poderia envolver uma gama de práticas ameríndias, já que o cuidado de si tem sua origem num fundo pré-filosófico xamânico.

O último dado é apontar uma desvalorização dessas práticas de si com o que o filósofo francês chamou de "momento cartesiano". Compreendemos não só uma exclusão dessas práticas - as práticas gregas analisadas por Foucault - no pensamento filosófico moderno, mas, também, diversas outras práticas não modernas, ou ainda, não ocidentais, que poderiam ser compreendidas como práticas de si deixadas de lado, desvalorizadas. Para sermos mais duros, diríamos que essas práticas são excluídas tanto da temática filosófica quanto de uma possibilidade existencial diferente da tradição cinza dos Humanos, da tradição cinza dos Modernos.

Seria fundamental uma filosofia a golpes de tacape para sermos duplamente plus intra. Assim, valorizaríamos tanto o retorno à Gaia quanto um retorno ao sujeito ${ }^{2}$ - e poderíamos pensar, também, que o futuro é a ancestralidade, que o tecnológico deve ser o primitivo e o bárbaro, assim, podemos sair tanto de uma perspectiva aceleracionista quanto de uma perspectiva do acrescimento. Este duplo retorno ao plus intra é exatamente o oposto à lógica do duplo plus ultra: a saída da Terra para colonização de um exoplaneta - como na maioria dos filmes norte-americanos com sua estética kantiana do sublime - e a valorização de um sujeito estruturalmente capaz da verdade, ou seja, sem a necessidade de uma modificação de si mesmo e vinculado à tradição de um cientificismo moderno. Esse cientificismo moderno estaria enamorado de um antropocentrismo que perpassa grandes nomes do pensamento filosófico ocidental como, por exemplo, Aristóteles, Kant e Heidegger. De qualquer forma, o que deveria ser afirmado é que neste período contemporâneo o homem perde o lastro ontológico clássico e medieval - o abandono do cosmocentrismo e do teocentrismo - que fundaria uma ética forte e que serviria de fundamento único. Daí que nos encontramos, sobretudo, numa configuração de mundo em que predomina a razão poética, a razão instrumental (ADORNO; HORKHEIMER, 2006) pensada como cálculo (herança cartesiana e hobbesiana) ou pensada como algoritmo, o modelo matemático, a ação sob os critérios da utilidade e da cientificidade vinculadas ao capital como valor soberano de sucesso que coaduna com a subjetividade do empresário de si.

\footnotetext{
${ }^{2}$ Quando falamos de um "retorno ao sujeito" não salientamos um retorno à filosofia do sujeito (a questão da identidade e da interioridade), mas, sim, pensamos esse termo em relação a determinados processos de subjetivação, a formas de modos de existência e, até mesmo, a individuações sem sujeito.
} 


\section{O CUIDADO E $A$ QUEDA DO CÉU}

O relato d'A queda do céu está envolto na questão da exigência de um cuidado, mesmo que seja por meio de uma narrativa que coloque o medo (phóbos) à tona como uma emoção (páthe) importante. Geralmente, quando se pensa o medo, o ponto abordado é como ele seria um afeto limitador, uma paixão triste no sentido spinozista, uma força que paralisa o sujeito até ele estar amarrado à inação. Este sentimento estaria estreitado com outro que é a covardia. Se pensarmos o contrário do medo encontramos a coragem e o destemor. A palavra coragem em latim deriva da palavra cor (“coração"). O órgão cardíaco seria a sede desse sentimento. Por sua vez, a palavra des-temor é aquele sem timor ("sem medo, sem temor"), que deriva de outra palavra latina interessante que é timere ("recear"), ou seja, aquele que tem medo receia algo, zela por algo, cuida de algo. O que há de grande é ter o medo na ponta dos lábios; assim, é essencial compreender n'A queda do céu um valor heurístico para o medo, ou ainda, pensarmos numa heurística do receio e do cuidado, ou ainda, numa ecologia do medo. Um medo ativo que não paralisa o sujeito nem se torna uma paixão triste, mas uma ecologia do medo que o impulsiona, um medo que cuida de algo. Assim sendo, o medo que nos interessa é um medo que se entrelaça ao zelo.

O medo deve ser sentido in concreto e sempre estar à altura da ameaça. Seja ela a ameaça vindoura ou a que já encontramos no real. O xamã Davi Kopenawa (KOPENAWA; BRUCE 2015, p. 494, grifo nosso) afirma que os brancos "não têm medo de desaparecer, porque são muitos". Os brancos não têm medo do fim do tempo, mesmo vivendo n'O tempo do fim, na Era Atômica ${ }^{3}$ e no antropoceno $^{4}$, ou ainda, no capitaloceno e na conhecida banalidade do mal ambiental evocada por cada negacionista. O xamã parece nos avisar que deveríamos ter medo da queda do céu, do seu desabamento, da catástrofe que é soturnamente democrática, pois compartilhada. Ela cairá sobre nós, mesmo que os seus efeitos sejam sentidos primeiramente em populações empobrecidas.

\footnotetext{
${ }^{3}$ É interessante notar que as narrativas apocalípticas surgem primeiramente no âmbito religioso, depois na Era Atômica e, mais recentemente, nas mudanças climáticas. Posto este dado, compreendemos que cada vez mais a narrativa apocalíptica foi secularizada. Diante dessa secularização compreendemos que o medo da bomba atômica foi substituído pelo medo do Humano e sua relação destrutiva diante da natureza.

${ }^{4} \mathrm{O}$ conceito de antropoceno é usado de forma cada vez mais comum para caracterizar uma nova era geológica. $\mathrm{O}$ termo é um neologismo constituído com o prefixo anthropo (humanidade) e o sufixo cene (novo). O termo foi cunhado pelo químico Paul Crutzen e o ecologista Eugene Stoermer e, apesar de o termo sofrer grandes contestações, parece não perder a sua força como um conceito operacional. Ver, por exemplo, Bonneuil; Fressoz, (2016).
} 
Talvez ainda não tenhamos sentido medo suficiente, talvez não tenhamos elaborado essa ecologia do medo. E nesse momento não se trata de desativar as amígdalas cerebrais para perder o medo, mas tê-las ativas o suficiente para trabalhar o medo, até mesmo o medo do que é supraliminar, ou do que poderíamos chamar de objetos supraliminares.

Günther Anders nos recorda que o subliminar estudado pela psicologia é um estímulo pequeno demais para produzir qualquer reação. Mas, o filósofo nos fala de um estímulo supraliminar. Este conceito nos remonta a um estímulo grande demais para produzir qualquer reação. Lembremos que Anders é um dos filósofos do pós-guerra preocupado com um mundo pós-Auschwitz e pós-Hiroshima. Uma análise que o autor faz é que a imaginação deixou de estar à altura da produção, e o sentimento, de estar à altura da responsabilidade. Quanto maior o efeito das ações, menos capazes de visualizar ou nos arrepender dos nossos atos, de sentilos, de nos responsabilizarmos por eles. Dito de outra forma: matar cem mil pessoas seria mais fácil que matar um homem cara a cara. Dito de forma ainda mais atual: assassinar milhares com um drone é mais fácil que matar um homem face a face. Assim sendo, gostaríamos de compreender a supraliminaridade como algo real e grande demais que, por sua vez, não gera uma reação no sujeito. Outro aspecto é compreendê-la como uma ação do indivíduo que vai muito além dele e que o aparta da sua responsabilidade - ele não se compreende como responsável da sua ação. Agora, para complementar essa ideia voltamos para alguns aspectos do conceito de hiperobjeto.

É com Timothy Morton que temos uma elaboração do que ele chama de hyperobjects (hiperobjetos). A filósofa Déborah Danowski num pequeno texto chamado $O$ hiperrealismo das mudanças climáticas e as várias faces do negacionismo faz um comentário sobre os hiperobjetos. Ela afirma que esses objetos desafiam a percepção que temos do tempo e do espaço "porque estão distribuídos de tal maneira pelo globo terrestre que não podem ser apreendidos diretamente por nós, ou então que duram ou produzem efeitos cuja duração extravasa enormemente a escala da vida humana conhecida" (DANOWSKI, 2012, p. 4). A autora dá alguns exemplos de hiperobjetos, como os materiais radioativos e a própria guerra atômica. Ainda mais interessante é a compreensão do aquecimento global (e as mudanças climáticas) como um hiperobjeto.

Daí que gostaríamos de compreendê-los como objetos supraliminares e caracterizá-los como um objeto não facilmente tangível como, por exemplo, um livro que tocamos, mas que perpassa uma grande elaboração teórica e uma gama de variáveis. Ao mesmo tempo, por esse objeto ser supraliminar, ele seria uma produção humana (no caso do clima, o antropoceno) da 
qual não saberíamos quais possíveis consequências, embora possamos vislumbrá-las. Outro dado é a questão da responsabilidade perdida quando o objeto é demasiado grande. Por último, não haveria nem um total vínculo afetivo, o sujeito não reage integralmente ao objeto supraliminar. Mas, o que gostaríamos de pensar aqui é que a narrativa d'A queda do céu é, também, uma forma de falar deste objeto supraliminar, pois os xamãs, de alguma forma viram que o céu está prestes a desabar e propuseram um cuidado para com a floresta, um zelo especial dos terranos com relação à Terra.

Não queremos remontar a toda a narrativa d'A queda do céu, mas é necessário enfatizar que o céu desabará. Os xapiri se vingariam dos homens, vingando a floresta cada vez mais desmatada. $O$ motivo da queda do céu é que quem segura o céu são os xamãs, e eles estão morrendo; estão sendo assassinados desde as primeiras invasões. Há uma falta de zelo com o humano, com o ambiente, com os animais e com a Terra, a cada momento isso fica mais alarmante, e os xamãs não poderiam mais segurar o céu. $O$ grande problema que encontramos é que os xamãs têm a função de criar uma espécie de cosmo na floresta e, com sua morte cada vez mais contínua, esse cosmo voltaria a ser um caos. Se os xamãs e índios morrerem, os brancos não ficariam sozinhos na Terra, com eles haveria uma quantidade enorme de seres maléficos que iriam "devorá-los, com tanta voracidade quanto suas fumaças de epidemia devoraram os nossos. Vão incendiar as suas terras, derrubar suas casas com vendavais ou afogá-los em enxurradas de água e lama" (KOPENAWA; ALBERT, 2015, p. 492, grifo nosso).

A floresta sem os xamãs não mais ficaria em pé; o céu seria coberto por nuvens escuras e não haveria mais o dia, não haveria mais silêncio na mata, a voz dos trovões ressoaria a todo o momento, o solo rasgaria, as árvores e os edifícios cairiam, a mata ficaria escura e fria. O céu rangeria, gemeria, e os espíritos cortariam seus pedaços a machadadas, até que desabasse totalmente. A terra onde os humanos vivem seria empurrada para o subterrâneo, eles virariam vorazes ancestrais ã̃patari (canibais). Os xapiri atirariam na terra o sol, a lua e as estrelas. Por fim, o céu ficaria escuro para sempre. É esse pesadelo que o ativismo de Kopenawa parece querer evitar, afirmando que "gostaria que os brancos escutassem nossas palavras e pudessem sonhar eles mesmos com tudo isso" (KOPENAWA; ALBERT, 2015, p. 491). Kopenawa configura-se em um semeador do medo; então, que temam a queda do céu! Trata-se de sentir in concreto o tempo do fim, para quiçá ser possível compreender o perigo, tendo, a cada momento, o medo mais próximo, mas um medo à altura 
do real perigo da queda do céu, pois esse medo poderia gerar um cuidado com a floresta, antes que tudo seja levado pela água e pela lama a la Samarco S.A Vale/BHP Billiton.

\section{A COSMOPOLÍTICA E A GUERRA DOS MUNDOS}

Adotemos agora a temática da cosmopolítica. Fazemos um retorno a esse tema via Isabelle Stengers, distanciando-nos do conceito do filósofo alemão Immanuel Kant a respeito de um jus cosmopoliticum; de um mundo comum a todos, de uma extensão universal de uma determinada humanidade já posta. É claro que nesse jus cosmopoliticum kantiano há um problema fundamental: a recusa de participar dessa universalidade; assim, há uma gama de recalcitrantes obrigados a participar dessa totalidade, seja por meio de uma docilização via interioridade constitucional do direito ou ainda de sua total representação como coisa. Na Ideia de uma história universal de um ponto de vista cosmopolita ou n'A paz perpétua kantiana não há espaço para a selvageria. Selvageria que significaria uma espécie de degradação do humano até a animalidade (SANTOS, 2008). O homem kantiano é o homem do aufklärung (esclarecimento), vinculado a uma virtude antropogenética. Trata-se: “do poder de constituir a humanidade do homem como um posto autorreferencial de eminência ontológica, imune a catástrofes (sobre-) naturais" (VALENTIM, 2013: p. 50).

O conceito de cosmopolítica de Isabelle Stengers, por sua vez, se aproxima, de forma filosófica, de Gilles Deleuze e, de forma literária, a Herman Melville e, ainda, de forma política, a um acontecimento político-cósmico. De Deleuze há o personagem conceitual do Idiota, lembrando que a significação da palavra idiota em grego é aquela ou aquele que não fala grego, ou seja, aquele que é compreendido como não civilizado. Para a filósofa, o murmúrio incompreensível do Idiota faz desacelerar, resistindo a uma situação apresentada, exigindo que não nos precipitemos, pois talvez haja algo mais importante. Daí Stengers voltar para a literatura de Herman Melville recordando o conto Bartleby, o escrevente.

Para Stengers o advogado do conto de Melville é a figura que a cosmopolítica tem que evitar, porque deseja que "Bartleby saia de sua abstenção, que se una ao comum, onde os seres humanos aceitam se comprometer" (STENGERS, 2015, p. 23). O advogado ainda quer “forçá[-lo] a fazer o que não prefere fazer" (p. 23). Se voltarmos ao conto de Melville, compreendemos que o personagem principal causa de fato um espanto, pois o advogado afirma que "havia algo em Bartleby que, estranhamente, não só me desarmava, mas, de modo 
espantoso, também me comovia e desconcertava" (MELVILLE, 2015, p. 70). Se a cosmopolítica tem que desviar do advogado é devido à necessidade de evitar a boa vontade individual e lhe dar uma significação coletiva; ou seja, assinalando um agenciamento em que se propõe a questão política, estaríamos ao lado de um acontecimento político-cósmico.

Para nós a cosmopolítica implicaria aberturas e fraturas múltiplas entre diversos mundos. Consequentemente, esse interstício se relacionaria a linhas duras, flexíveis, e linhas de fuga. Seguimos, ademais, em consonância com Marisol de la Cadena afirmando que a cosmopolítica se constitui de diversos mundos que nos convocam a pensar o que para nós são as montanhas, os rios, as árvores, as formas naturais e, claro, também, o não humano. Para Marisol de la Cadena essa política do cosmo não implicaria, por sua vez, um universalismo ou relativismo, mas a articulação de mundos existentes. Desse modo, entende-se que "a cosmopolítica encontra sua referência empírica no slogan zapatista por um mundo onde caibam muitos mundos, slogan que foi retomado pelo Fórum Social Mundial" (DE LA CADENA, 2012, p. 3, grifo nosso).

Refletindo a respeito desses mundos, da construção ocidental e da construção ameríndia com os seus interstícios, poderíamos analisar a Guerra dos Mundos como apontada por Bruno Latour. Voltar para a reflexão produzida por Latour é explicitar a catástrofe em que vivemos. Um dos nomes desta época catastrófica é o antropoceno, a compreensão que somos (nós Humanos) uma força geológica destrutiva. De Latour e dessa Guerra dos Mundos podemos tomar dois pontos importantes que são: 1) reconhecer os inimigos e os amigos; 2) e ter que declarar essa Guerra. A Guerra seria entre os Humanos e os Terranos, sendo que os "Humanos" são genericamente associados ao pensamento Moderno. A filósofa Déborah Danowski e o antropólogo Eduardo Viveiros de Castro são ainda mais incisivos que Latour e não fazem tão-somente uma caracterização genérica dos Humanos. Ambos nomeiam estes inimigos citando Chevron, Exxon, BP, Shell, Saudi Aramco, GazProm, a Statoil norueguesa, a brasileira Petrobrás - e nomes como Monsanto, Dupont, Syngente, Bayer, Cargill, Bunge, Dow, Vale, Nestlé, também deveriam ser citados. É claro que a lista é longa e perpassa tantos outros nomes que compõem a linha da frente dos Humanos. Os Terranos, por sua vez, seriam mais misteriosos, haveria uma maior dificuldade de reconhecê-los, posto que talvez sejam aquilo que Félix Guattari procurava em suas viagens. Guattari buscava um povo que falta, ou ainda, um povo por vir. Claro que aqui nos colocamos do lado dos Terranos, os não 
modernos, ou seja, temos o foco na cultura ameríndia, nos indígenas, no sentido preciso do termo, sendo não aquele que possui a terra, mas sim aquele que é da terra.

Postos os integrantes dessa Guerra em foco, seria oportuno, agora, declará-la, torná-la explícita, porque é somente com essa declaração de Guerra que haveria o início das negociações de paz. Voltamos ao tema de uma Geo-política, de uma Gaia-política. Deveríamos pensar nessa Guerra dos Mundos juntamente com uma política que não pensa tão-só o humano. Não é mais possível dissociar o humano da natureza, do não humano, de uma política cósmica, de uma cosmopolítica. Incluímos a ética como um aspecto do que aqui compreendemos como cosmopolítica. Não uma ética solitária, na feitura solipsista e narcísica de si mesmo a la Descartes, mas, sim, uma ética atravessada pela presença do Outro. Lembremo-nos que o cuidado de si não tem o intuito de uma fuga passiva da realidade, mas de preparar o eu para os acontecimentos do mundo. Talvez devêssemos dizer que se trata de construir uma cabana no meio da floresta. Fazer-se uma fortaleza.

\section{UM CUIDADO DE SI RADICALMENTE FILOSÓFICO}

O filósofo Michel Foucault mudou muito o estilo das suas últimas obras, tanto no que diz respeito aos temas quanto ao seu estilo de escrita. Os seus estudos eram referentes ao período moderno inicial e ao período moderno. Todavia, suas últimas obras são geralmente caracterizadas por um retorno à Grécia Antiga e ao Império Romano. Tomemos, por exemplo, os três últimos volumes da História da sexualidade, ou ainda, o curso $A$ hermenêutica do sujeito. Tais obram trazem um estudo filosófico e histórico sobre a moralidade sexual e uma concepção particular de ética. O mesmo estudo envolve uma percepção de uma situação do presente, apontando que a ética seria interessante para repensarmos nossa própria relação com uma produção de subjetividade no presente.

Quando pensamos os problemas de uma ética na e para a sociedade contemporânea é preciso compreender que perdemos o já citado lastro ontológico clássico e medieval, o cosmocentrismo antigo e o teocentrismo da Idade Média que fundava uma "ética forte". No entanto, no mundo contemporâneo há lugares para a tentativa de uma produção ética, mesmo que esses espaços não se coloquem como fundadores de éticas como, por exemplo, a nossa economia política, o direito e a ciência materialista. Estas são as principais instâncias produtoras de formas de comportamento, produtoras de éticas no contemporâneo. Só que elas não implicam uma autonomia do sujeito, mas, sim, uma heteronomia. Daí a importância de 
Foucault retornar a uma estética da existência, o retorno ao treinamento permanente de si mesmo e as maneiras que transformam o modo de ser de um sujeito.

Vemos essa elaboração começar a ganhar forma no Collége de France, no curso de 1981-82. Nas primeiras aulas, Foucault assinala Sócrates como aquele que evoca o "cuidado de si". 5 Sócrates seria e permaneceria como o grande mestre do cuidado de si mesmo. De fato, o cuidado de si neste momento socrático-platônico exigiria um mestre; porém, essas práticas têm muitas formas aquém e além da figura exuberante, estranha, indescritível - átopos - de Sócrates.

Podemos pensar essas práticas de si para além do quadro histórico do cuidado de si apresentado por Foucault, já que ele mesmo nos aponta práticas de si pré-filosóficas. Nesse sentido seria necessário salientar o seguinte fragmento d'A hermenêutica do sujeito:

\begin{abstract}
Bem, há pouco, ao falar das técnicas de si e de sua preexistência à reflexão platônica sobre a epiméleia heautoû [cuidado de si], eu tinha em mente, e me esqueci de lhes mencionar, que existe um texto, um dos raros textos, parece-me, um dos raros estudos nos quais esses problemas são um pouco abordados em função da filosofia platônica: trata-se do livro de Henri Joly intitulado Le Renversement platonicien Lógos-Epistéme-Pólis. Há nele cerca de uma dúzia de páginas sobre esta preexistência, ali atribuida à "estrutura xamanistica" - palavra discutivel, mas isso é irrelevante. Ele insiste na preexistência de algumas dessas técnicas na cultura grega arcaica (técnicas de respiração, técnicas do corpo, etc.). Pode ser tomado como referência. Em todo caso, é um texto que me trouxe algumas ideias, e fui desatento em não citá-lo antes. (FOUCAULT, 2014, p. 61, grifo nosso).
\end{abstract}

Seria difícil precisar quais são essas "algumas ideias" que Foucault teve dessas práticas de si que são anteriores ao texto platônico, que são anteriores a Sócrates, mas uma das hipóteses poderia ser que o cuidado de si é anterior à elaboração filosófica que ganha com Sócrates a medalha filosófica. Outro momento vital para a nossa aproximação se dá na "Aula de 17 de março de 1983" em que encontramos um comentário extenso sobre o xamanismo. A elaboração de Foucault se apresenta da seguinte maneira:

Poderíamos tentar realizar um exame um pouco sistemático disso tudo e, se quisermos, empregando uma palavra relativamente solene que colocaria entre aspas, realizar uma espécie de "etnologia da ascética": comparar os diferentes exercícios entre si, seguir sua evolução, sua difusão. Há por exemplo um problema que me parece muito interessante, levantado por Dodds, retomado por Vernant e por Joly, e que suscitou uma discussão, ou em todo caso que provocou o ceticismo de Hadot: o problema da continuidade entre os exercícios de origem possivelmente xamânica, que apareceram na Grécia por volta dos séculos VII-VI, e os exercícios espirituais que se desenvolvem na filosofia grega propriamente dita. A hipótese de Dodds,

\footnotetext{
${ }^{5}$ Ver, além disso, Hadot (2014).
} 
retomada por Vernant e por Joly, considera que ao entrarem em contato com as civilizações do nordeste europeu (graças à navegação no mar Negro), no século VII, os gregos encontraram-se em presença de certas práticas xamânicas e de técnicas de si próprias daquela forma de cultura, dentre as quais estavam: regimes de abstinências-proezas (até que ponto se suportará a fome, o frio, etc. ?); também o sistema de abstinências-proezas (disputa para saber quem irá mais longe nesse gênero de perder o fôlego, respirar o menos possível para tentar concentrar-se e, de algum modo, dispensar-se o menos possível no mundo exterior); meditação sobre a morte, sob a forma de uma espécie de exercício pelo qual se desprenderia a alma do corpo, e de certo modo se anteciparia a morte - exercícios que os gregos, portanto, teriam conhecido através e a partir das culturas xamânicas. São exercícios, sempre segundo Dodds, Vernant e Joly, cujos traços encontraríamos nos primeiros diálogos socráticos, em que vemos Sócrates suscitar admiração de seus contemporâneos e dos que o cercam: assim, na batalha de Potideia, quando fica sozinho na noite, no frio, imóvel, nada sentindo e nada experimentando em torno de si. São formas de práticas de si, de técnicas de si que estariam assim atestadas em certos aspectos do personagem de Sócrates. (FOUCAULT, 2014, p. 135).

Com essa passagem, Foucault salienta os principais autores ${ }^{6}$ que focam em uma continuidade das práticas de si xamânicas para as práticas de si gregas. Foucault considera Sócrates o mestre do cuidado de si, já que ele incitaria todos em Atenas a examinar a sua própria vida, e morre por isso. Sócrates, além disso, seria o mestre do cuidado de si quando pensávamos que é com ele que esse preceito ganha um caráter filosófico, principalmente nas obras Apologia de Sócrates e Alcibíades. Porém, nem por isso as outras práticas de cuidado de si, anteriores ao período socrático-platônico, deveriam ser esquecidas, ou ainda, acreditamos que não deveríamos caracterizá-las com um "pré" alguma coisa, sendo que, geralmente, este "pré" remonta a um aspecto não somente anterior temporalmente, mas, sobretudo, a um ponto inferior qualitativamente.

De qualquer forma, afirmamos que as práticas de si são essencialmente xamanísticas e ganharam, posteriormente, contornos de um filosófico cuidado de si; seja com Sócrates ou, ainda, no momento helenístico e romano e o período inicial do cristianismo. Mas haveria outros cuidados e práticas de si aquém e além do saber filosófico ou, ainda, deveríamos parar com os pudores conceituais e afirmar que aquelas práticas ditas "pré-filosóficas" por Foucault são radicalmente filosóficas.

\footnotetext{
${ }^{6}$ Este debate ganha algumas páginas na obra de Pierre Hadot $O$ que é a filosofia antiga?. Hadot (2014, p. 262) aponta que desde K. Meuli e E. R. Dodds houve uma tentativa de "representação dos filósofos gregos sobre a alma, sobre a separação entre alma e corpo, também sobre a origem das técnicas de concentração espiritual, das representações de viagens da alma fora do corpo, desde M. Eliade, a origem igualmente das técnicas de êxtase". Hadot, por sua vez, se mostra reticente a essas explicações. Não obstante as ponderações de Hadot, o xamanismo é uma das melhores vias para compreensão dos exercícios espirituais anteriores à figura socrático-platônica. Então, seguimos não somente com os filósofos e antropólogos citados por Hadot que produzem argumentos consistentes ao xamanismo e sua relação com a cultura grega, mas, também, deveríamos evocar a produção de Henry Joly e, sobretudo, o trabalho arqueológico e neuropsicológico elaborados por Jean-Clottes e David LewisWilliams.
} 


\section{AS PRÁTICAS DE SI E A INICIAÇÃO XAMÂAICA}

As práticas de si e a iniciação xamânica podem ser vistas no percorrer d'A queda do céu. Neste momento fazemos uma breve análise sobre a iniciação ao xamanismo, compreendendo-a como práticas de si, como uma estética da existência, assim, pensamos na iniciação xamânica e pensamos num determinado acesso à verdade. Não faremos uma análise comparativa entre a prática de si socrática e a prática de si ameríndia ${ }^{7}$. Porém, enfatizaremos determinadas técnicas das práticas yanomami que geraram, por exemplo, outra subjetividade capaz de ser compreendida como um cuidado de si ameríndio, pois encontramos determinadas práticas que o sujeito faz e, por meio delas, por meio do preço que o sujeito paga, há um efeito de retorno. No caso d'A queda do céu esse retorno pode ser compreendido como, por exemplo, o momento em que o xamã sai do próprio corpo e sobrevoa a floresta. Assim, ele obtém toda uma esfera de conhecimento que o transforma e o modifica.

De qualquer modo, gostamos de pensar $A$ queda do céu... como um grande manifesto político-ameríndio. Devido, também, à sua grandiosidade filosófica, com certeza, ele será fecundo numa gama enorme de abordagens que já são produzidas. Desta maneira, vamos abordar tão-somente o capítulo d'A queda do céu..., que narra a iniciação ao xamanismo. Focamos em determinados aspectos e perdemos a amplitude política e emocional da formação de Davi Kopenawa. Esse caminho aponta uma apresentação célere de algumas práticas de si que transformam o sujeito, que fazem-no conhecer determinada verdade. É claro que a apresentação desses pontos se torna precária, mas entendemos como essencial para uma aproximação da compreensão das práticas xamânicas como uma ética.

Enfatizemos alguns aspectos da iniciação xamânica de Kopenawa. Salientemos certos pontos: 1) primeiro, a necessidade de um mestre, no caso, o sogro de Kopenawa; 2) segundo, a exigência de um ambiente composto por um silêncio e uma atenção diferenciada; 3) terceiro, a utilidade de determinada dieta que envolve, por sua vez, uma limpeza ou higienização do corpo; 4) por último, a atenção auditiva para o diálogo com os espíritos, mas, também, uma reorganização do próprio corpo.

\footnotetext{
${ }^{7}$ É interessante observar que Foucault faz uma análise das práticas de si ocidentais e as modificações que ocorrem na subjetividade ocidental. Assim, quando pensamos num período pré-filosófico do cuidado de si, ou ainda, numa prática de si ameríndia, deveríamos apontar, primeiramente, que não se trata de uma mesma constituição de sujeito. O "si" das práticas de si ameríndias, dessa forma, não poderia ser nem a alma-substância nem a alma-sujeito da cultura ocidental, mas, sobretudo, estamos diante de outra ideia de corporalidade como um invólucro com fronteiras permeáveis que ajudam a constituir o que se chama de "pessoa".
} 
A respeito da questão de o mestre que exerce essa função ser o sogro de Kopenawa: ele é um experiente xamã que conduz o iniciante ao processo de transformação do sujeito. Os espíritos já percorriam os sonhos de Kopenawa desde que ele era apenas uma criança. Ele narra que na sua infância tinha vários pesadelos, e não sabia do que falavam. É exatamente o xamã quem vai aclarar a situação para Kopenawa, explicando o motivo daqueles sonhos e a relação que ele tinha com os espíritos, os xapiri. Era a hora de Kopenawa também se tornar um xamã, de aprender a curar, de realmente conhecer a força da yãkoana. Sobre a yãkoana, salientamos que é a substância que gera um "estado não ordinário de consciência", mas talvez seja pouco usarmos o termo da filosofia da mente para falar de todas as alterações produzidas pela yãkoana (que não está somente relacionada à esfera da consciência). Trata-se, sobretudo, do que está além da consciência ou de um multinaturalismo. Estamos diante de outra ontologia que não a Moderna. A yãkoana é tanto o alimento dos espíritos como, além disso, uma forma de passagem para encontrá-los; e é o xamã que apresenta ao iniciado as doses - e a possivel overdose - de yãkoana.

A narrativa d'A queda do céu nos mostra um determinado ambiente para a iniciação do xamã. Nenhum lugar especial: Kopenawa ficava jogado no chão enquanto os outros passavam ao seu redor. O que se coloca é a necessidade de um determinado silêncio quando se usa a yãkoana. Os espíritos, os xapiri, têm uma casa silenciosa. No xamã existe uma atenção para o silêncio, a procura de outra companhia, outra sonoridade, talvez, um espaço mais liso. Ailton Krenak afirma que o seu povo ensina os seus filhos a passarem suavemente sobre a Terra, como um pássaro que faz um voo no céu e que não deixa rastros. Procura-se uma suavidade, mas uma suavidade tão intensa que possa mudar até mesmo o ruído da própria cultura indígena.

Um dado importante para a iniciação xamânica diz respeito às práticas para uma higienização, para uma limpeza. Tanto uma limpeza corporal vinculada à alimentação quanto uma limpeza corporal vinculada a uma abstinência sexual. Os xapiri não suportam o fedor de carne podre ou o cheiro do sexo, sendo, desta maneira, preciso limpá-lo. Os espíritos chegam a limpar a pessoa, os resíduos de carne, o cheiro da cópula, a boca, o fedor dos excrementos e, por último, os espíritos o fazem renascer como uma criança, o sujeito volta vermelho de sangue do parto e é indispensável limpá-lo ou, ainda, os espíritos o recobrem com uma nova pele e rasgam o seu peito para que lá possam morar mais espíritos. 
Outra coisa que pode acontecer é os xapiri o rasgarem, deceparem, decapitarem e mudar o seu corpo, lavar, limpar, refazer, re-orgão-nizar o próprio organismo. Porém, vamos novamente para a atenção para com os xapiri, pois é melhor aprender a "dialogar" com eles.

A ideia da limpeza retorna neste diálogo ou, ainda, na tentativa de aproximação do iniciado com os espíritos. A atenção, novamente, tem que ser intensa. O pensamento ganha determinada calma. É imperativo uma limpeza auditiva, reconhecer o canto, as palavras, os sons dos xapiri; é necessário ainda tentar imitar estes sons, assemelhar-se a eles. Em uma bela passagem, Kopenawa diz que, ao imitar os cantos dos espíritos, em determinado momento já não sabia diferenciar a sua voz do canto dos espíritos. A dissonante ópera de múltiplas camadas ganha força unívoca e passa a existir no xamã em composição com os espíritos.

Postos estes elementos da iniciação xamânica, podemos entender algumas práticas exercidas por Kopenawa à procura de uma específica alteração do sujeito em busca de uma verdade que é apresentada pelos espíritos, pelos xapiri. Esses elementos - e tantos outros que não foram salientados aqui - compõem algumas práticas para o processo de se tornar um xamã, um “enfermeiro" para o seu povo.

$\mathrm{O}$ alcance da verdade do sujeito, nesse momento, aconteceu por uma modificação dele, por meio dos exercícios, por uma determinada atenção consigo mesmo, em última instância, por um cuidado de si ameríndio. É interessante notar que Foucault, em suas últimas produções teóricas, volta-se principalmente para as questões de uma estética da existência; porém, esse retorno se dá pensando nos filósofos gregos - seria potente ver outras práticas de si não gregas - e em uma mudança de relação no alcance do sujeito a determinada verdade.

\section{DUPLAMENTE PLUS INTRA}

Quando pensamos na obliteração das práticas de si - e de forma correlata pensamos numa desqualificação das práticas xamânicas -, Foucault salienta uma mudança que denominou com muitas aspas de "momento cartesiano". Mas é preciso muita prudência, porque a relação com a verdade que é modificada não se apresenta de forma demasiadamente específica e datada, não se instala tão-somente com o cogito cartesiano, uma vez que encontraríamos aspectos em Aristóteles e, também, na teologia. Porém, é possível enfatizar aspectos desse momento para a compreensão da mudança no acesso à verdade e, de forma correspondente, uma mudança da ética na história do pensamento. Temos que retornar à ideia de espiritualidade para a compreensão desse momento. 
Ainda nas páginas iniciais d'A hermenêutica do sujeito, na aula de 6 de janeiro de 1982, Foucault aponta três características da espiritualidade que poderíamos resumir da seguinte forma: 1) a verdade não é dada ao sujeito por um simples ato de conhecimento; é preciso uma modificação do sujeito, sendo fundamental que ele se transforme, que ele se desloque, ou seja, que em certa medida ele já não seja ele mesmo, pois o sujeito inicialmente não teria acesso à verdade; 2) essa transformação do sujeito (que o tira do seu status) pode ser feita de diversas maneiras; Foucault chama esse movimento muito genericamente de éros (amor); 3) o último dado postulado pela espiritualidade é o seu efeito de retorno, pois há um efeito de retorno da verdade sobre o sujeito: "a verdade é o que ilumina o sujeito; a verdade é o que lhe dá beatitude; a verdade é o que lhe dá tranquilidade de alma" (FOUCAULT, 2014, p. 16).

Diante dessa concepção de espiritualidade reafirmamos que no acesso à verdade há algo que completa o sujeito, que o transfigura, modificando-o enquanto sujeito. Todavia, há uma mudança histórica no que corresponde a esse acesso da verdade que é o que salientávamos como "momento cartesiano". A grande diferença produzida entre esse momento em que é essencial uma transformação para acessar a verdade em outro momento, é que, na modernidade, para se ter um acesso à verdade é preciso tão-somente o conhecimento, visto que a verdade já está posta pelo aparelho cognitivo do sujeito.

Aquele que procura a verdade não tem o efeito de retorno que havíamos salientado na definição de espiritualidade, pois a verdade parece ser secularizada. Foucault não deixa de afirmar que não haja condições para a obtenção da verdade; essas condições ainda existem pensemos nos elementos para a produção da ciência como verdade -, mas são outras as formas e essas condições são internas ao ato de conhecimento. Dessa mudança, Foucault tem uma importante conclusão a respeito da verdade e, além disso, de uma determina posição com relação à ética:

Tal como doravante ela é [o acesso a verdade] a verdade não será capaz de salvar o sujeito. Se definirmos a espiritualidade como o gênero de práticas que postulam que o sujeito, tal como ele é, não é capaz de verdade, mas que a verdade, tal como ela é, é capaz de transfigurar o sujeito, diremos então que a idade moderna das relações entre sujeito e verdade começa no dia em que postulamos que o sujeito, tal como ele é, é capaz de verdade, mas que a verdade, tal como ela é, não é capaz de salvar o sujeito. (FOUCAULT, 2014, p. 19). 
De fato, trata-se, após o momento cartesiano, de uma verdade que não vai alterar o sujeito, uma verdade sem o efeito de retorno provocado pelas práticas de si. Uma verdade que não seria capaz de salvar o sujeito, não mais a iluminação, não mais a beatitude, não mais a tranquilidade da alma, não mais a verdade que volta para o sujeito etc. Esse novo tipo de acesso à verdade, por sua vez, gerou uma obliteração das práticas de si, do cuidado de si. Seja quando pensamos um cuidado grego, ou ainda, um cuidado de si ameríndio. É a espiritualidade chegando perto do seu fim. Portanto, não apenas um esforço de resistência, mas agora com tacape diante dos Humanos. Esse esforço é contínuo na nossa Gaia-política, em que se tece uma cartografia da Guerra no antropoceno. Essa Gaia-cartografia é preciso tanto para uma relação não moderna com a $\mathrm{T}(\mathrm{t})$ erra e consigo mesmo, assim: duplamente plus intra.

\section{REFERÊNCIAS}

ADORNO, Theodor; HORKHEIMER, Max. Dialética do esclarecimento. Tradução Guido Antônio de Almeida. Rio de Janeiro: Jorge Zahar, 2006.

ANDERS, G. Nosotros, los hijos de Eichmann. Tradução Vicente Gómes Ibánez. Barcelona: Paidós, 2001.

ANDERS, G. Teses para a era atômica. Tradução Alexandre Nodari e Déborah Danowski. Sopro, n. 87, 2013. Disponível em: http://www.culturaebarbarie.org/sopro/outros/anders.html. Acesso em: 27 dez. 2017.

BONNEUIL, Christophe; FRESSOZ, Jean-Baptiste. The Shock of the Anthropocene. Tradução David Fernbach. London/New York: Verso Books, 2016. (Edição digital).

CASTRO, E. Introdução a Foucault. Belo Horizonte: Autêntica, 2014.

CHAKRABARTY, D. O clima da história: quatro teses. Tradução organizada por Idelber Avelar, Sopro, n. 91, 2013. Disponível em: http://www.culturaebarbarie.org/sopro/n91.html. Acesso em: 27 dez. 2017.

CRARY, J. 24/7: capitalismo tardio e os fins do sono. Tradução Joaquim Toledo Jr. São Paulo: Cosac Naif, 2014.

DANOWSKI, D. O hiperrealismo das mudanças climáticas e as várias faces do negacionismo. Sopro, n. 70, 2012. Disponível em: http://www.culturaebarbarie.org/sopro/n70scribd.pdf. Acesso em: 27 dez. 2017.

DANOWSKI, D; Viveiros de Castro, E. Há mundo por vir? Ensaio sobre os medos e os fins. Desterro [Florianópolis]: Cultura e Barbárie, Instituto Socioambiental, 2014. 
DE LA CADENA, M. Seminar Proposal. Indigenous cosmopolitics: dialogues about the Reconstitution of worlds. 2012. Disponível em: http://sawyerseminar.ucdavis.edu/files/2012/01/Sawyer_Seminar_Proposal.pdf. Acesso em: 27 dez. 2017.

DELEUZE, G. Foucault. Tradução Claudia San’Anna Martins; revisão de tradução Renato Ribeiro. São Paulo: Brasiliense, 2005.

DELEUZE, G.; GUATTARI, F. O anti-Édipo: capitalismo e esquizofrenia. Tradução Luiz B. Orlandi. Rio de Janeiro: Ed. 34, 2010.

DELEUZE, G.; PARNET, C. Diálogos. Tradução Eloisa Araújo Ribeiro. São Paulo: Escuta, 1998.

FOUCAULT, M. A hermenêutica do sujeito. São Paulo: Martins Fontes, 2014.

HADOT, Pierre. O que é a filosofia antiga? Tradução Dion Macedo. São Paulo: Loyola, 2014.

HARAWAY, D. Antropoceno, Capitaloceno, Plantationoceno, Chthuluceno: fazendo parentes. ClimaCom: cultura científica. 3(5). 2016. Disponível em:

http://climacom.mudancasclimaticas.net.br/wpcontent/uploads/2014/12/dossie_climacom_vul nerabilidade.pdf. Acesso em: 27 dez. 2017.

KANT, I. Ideia de uma história universal de um ponto de vista cosmopolita. Tradução Rodrigo Naves e Ricardo R. Terra. São Paulo: Martins Fontes, 2010.

KOPENAWA, Davi; BRUCE, Albert. A queda do céu: palavras de um xamã yanomami. Tradução. Beatriz Perrone-Moisés: São Paulo: Companhia das Letras, 2015.

LATOUR, B. Para distinguir amigos e inimigos no tempo do Antropoceno. Revista de Antropologia. 57(1): p. 11-31. 2014. Disponível em:

http://www.revistas.usp.br/ra/article/view/87702. Acesso em: 27 dez. 2017.

LEMOS, F. Kant e o monstro. Kriterion, Belo Horizonte, jan./jun. p. 189-203, 2014.

LEOPOLDO, R. Good kill: Guerra pós-heroica e psicopatologia do drone. Sapere AudeRevista de Filosofia, v. 7, n. 14, p. 827-844, 2016a. Disponível em:

http://periodicos.pucminas.br/index.php/SapereAude/article/view/12423. Acessado: 27 de dezembro de 2017.

LEOPOLDO, R. O sombrio sonho d'A queda do céu. ClimaCom: cultura científica. 3(5). 2016b. Disponível em:

http://climacom.mudancasclimaticas.net.br/wpcontent/uploads/2014/12/dossie_climacom_vul nerabilidade.pdf. Acesso em: 27 dez. 2017.

MARX, Karl. O capital. Tradução Reginaldo Sant'Anna. Rio de Janeiro: Civilização Brasileira, 2017. 
MELVILLE, Herman. Bartleby, o escrevente: uma história de Wall Street. Tradução de Tomaz Tadeu. Ilustração Javier Zabala. Belo Horizonte: Autêntica, 2015.

NETO, M. P. Esquecer o neoliberalismo: o aceleracionismo como terceiro espírito do capitalismo. Cadernos IHU Ideias, vol. 14, n. 245, 2016.

NETO, M. P. Política no fim do mundo. Piseagrama, Belo Horizonte, n. 8, p. 42-51, 2015.

ROHDEN, Luiz; Kussler, Leonardo Marques. Philosophizing as care of the self: an ethicalpolitical spiritual exercise. Trans/form/ação, Marília, v. 40, n. 3, p.93-112, jul./set., 2017.

SANTOS, B. S. A filosofia à venda, a douta ignorância e a aposta de Pascal. Revista Crítica de Ciências Sociais, n. 80. 2008. Disponível em:

http://www.ces.uc.pt/myces/UserFiles/livros/47_Douta\%20Ignorancia.pdf. Acesso: 27 dez. 2017.

SRNICEK, N; Williams, A. Manifesto aceleracionista. Lugar Comum, número 41. p. 269279, 2015. Disponível em:

http://uninomade.net/wpcontent/files_mf/111404140923Manifesto\%20aceleracionista\%20\%20Alex\%20Williams\%20e\%20Nick\%20Srnicek.pdf. Acessado: 27 de dezembro de 2017.

STENGERS, Isabelle. No tempo das catástrofes. São Paulo: Cosac Naify, 2015.

STENGERS, Isabelle. The cosmopolitical proposal. In: LATOUR, B.; WEIBEL, P. (ed.). Making things public: atmospheres of democracy. Cambridge: The MIT Press. 2005. p. 9941004.

TAYLOR, Charles. A ética da autenticidade. Tradução Talyta Carvalho. São Paulo: Realizações Editora, 2011.

VALENTIM, M. A. A sobrenatureza da catástrofe. Revista Landa, v. 3, n. 1, UFSC, Florianópolis, 2014.

VALENTIM, M. A. Extramundanidade e sobrenatureza. Natureza Humana-Revista Internacional de Filosofia e Psicanálise, v. 15, n. 2, 2013. Disponível em:

http://revistas.dwwe.com.br/index.php/NH/article/viewFile/31/16. Acesso em: 27 dez. 2017.

WADE, S. Foucault in California: a true story - wherein the great french philosopher drops acid in the valley of death. California: heyday, 2019.

WHITEHEAD, M. Environmental transformation: geography of the anthropocene. New York: Routledge, 2014. 